\title{
Cross-cultural validity of a dietary questionnaire for studies of dental caries risk in Japanese
}

\author{
Chikako Shinga-Ishihara' ${ }^{1}$ Yukie Nakai ${ }^{1 *}$, Peter Milgrom² ${ }^{2}$ Kaori Murakami ${ }^{1}$ and Michiyo Matsumoto-Nakano ${ }^{1}$
}

\begin{abstract}
Background: Diet is a major modifiable contributing factor in the etiology of dental caries. The purpose of this paper is to examine the reliability and cross-cultural validity of the Japanese version of the Food Frequency Questionnaire to assess dietary intake in relation to dental caries risk in Japanese.

Methods: The 38-item Food Frequency Questionnaire, in which Japanese food items were added to increase content validity, was translated into Japanese, and administered to two samples. The first sample comprised 355 pregnant women with mean age of $29.2 \pm 4.2$ years for the internal consistency and criterion validity analyses. Factor analysis (principal components with Varimax rotation) was used to determine dimensionality. The dietary cariogenicity score was calculated from the Food Frequency Questionnaire and used for the analyses. Salivary mutans streptococci level was used as a semi-quantitative assessment of dental caries risk and measured by Dentocult SM. Dentocult SM scores were compared with the dietary cariogenicity score computed from the Food Frequency Questionnaire to examine criterion validity, and assessed by Spearman's correlation coefficient $\left(r_{s}\right)$ and Kruskal-Wallis test. Test-retest reliability of the Food Frequency Questionnaire was assessed with a second sample of 25 adults with mean age of $34.0 \pm 3.0$ years by using the intraclass correlation coefficient analysis.

Results: The Japanese language version of the Food Frequency Questionnaire showed high test-retest reliability $(I C C=0.70)$ and good criterion validity assessed by relationship with salivary mutans streptococci levels $\left(r_{s}=0.22\right.$; $p<0.001$ ). Factor analysis revealed four subscales that construct the questionnaire (solid sugars, solid and starchy sugars, liquid and semisolid sugars, sticky and slowly dissolving sugars). Internal consistency were low to acceptable (Cronbach's alpha $=0.67$ for the total scale, $0.46-0.61$ for each subscale). Mean dietary cariogenicity scores were $50.8 \pm 19.5$ in the first sample, $47.4 \pm 14.1$, and $40.6 \pm 11.3$ for the first and second administrations in the second sample. The distribution of Dentocult SM score was 6.8\% (score = ), 34.4\% (score = 1), 39.4\% (score = 2), and 19.4\% $($ score $=3)$. Participants with higher scores were more likely to have higher dietary cariogenicity scores $(p<0.001$; Kruskal-Wallis test).
\end{abstract}

Conclusions: These results provide the preliminary evidence for the reliability and validity of the Japanese language Food Frequency Questionnaire.

Keywords: Food frequency questionnaire, Cariogenic food, Diet, Reliability, Validity, Mutans streptococci

\section{Background}

Diet is a major modifiable contributing factor in the etiology of dental caries. In a healthy individual, new carious lesions do not develop and active caries lesions arrest with lower consumption of cariogenic foods. The frequent consumption of fermentable carbohydrate, especially sugar, has an important role in development of

\footnotetext{
* Correspondence: yukien@md.okayama-u.ac.jp

'Department of Pediatric Dentistry, Okayama University Graduate School of Medicine, Dentistry and Pharmaceutical Sciences, Okayama, Japan Full list of author information is available at the end of the article
}

dental caries [1-3]. The Vipeholm Study, in which hospitalized mentally ill patients in Sweden were fed large amounts of sticky sugar sweetened foods, demonstrated the primary role of diet in the pathogenesis of dental caries [3]. Palmer and colleagues, using a short diet survey focused on the frequency of sweetened food intake, that children whose teeth were heavily colonized by the dental caries pathogen Streptococcus mutans had higher food cariogenicity scores [4]. Recently, Evans and colleagues reported preliminary results on a diet

\section{Biomed Central}

(c) 2014 Shinga-Ishihara et al.; licensee BioMed Central Ltd. This is an Open Access article distributed under the terms of the Creative Commons Attribution License (http://creativecommons.org/licenses/by/2.0), which permits unrestricted use, distribution, and reproduction in any medium, provided the original work is properly cited. The Creative Commons Public Domain Dedication waiver (http://creativecommons.org/publicdomain/zero/1.0/) applies to the data made available in this article, unless otherwise stated. 
questionnaire including sugar sweetened beverages and focused younger children in an attempt to discriminate between children with and without severe early childhood caries [5]. A snacking culture, in which sweetened foods and beverages are consumed frequently, has increasingly been adopted in Asian countries as economic growth increased access to foreign culture.

Previous research examining the relationship between diet/nutrition and oral health among the Japanese used questionnaires that were not specifically designed for oral health studies. A semi-quantitative food frequency questionnaire [6], which consists of 5 food categories such as main meals, sugar, main dish, salt, and oil intake consumed during preceding week, was used to examine the relationship between the intake of dairy products and root caries in the elderly [7]. No assessments of reliability and limited data on validity were reported. A diet history questionnaire, consisting of 110 food items selected mainly from a food list used in National Nutrition Survey of Japan, was developed for use in health education. Tanaka and colleagues used this diet history questionnaire to hypothesize a negative relationship between tooth loss prevalence and the intake of magnesium [8], and also between tooth loss and the insoluble fiber foods [9] among Japanese women. However, the reliability of this instrument was not reported. Validity was established by comparison with 3-day diet record [10]. The Mini Nutrition Assessment (MNA) short-form [11,12] was used to assert the relationship between oral health status, swallowing function, nutritional status, cognitive ability and the activities of daily living [13]. The MNA is a well-known nutritional screening instrument designed for older people and the reliability and cross-cultural validity has been tested in Europe and USA [11]. Its reliability and validity has been partially assessed [14].

The interest in dietary counseling or interventions to reduce caries risk has been rising on a dental practice basis in Japan, although such approaches are not commonly done yet [15]. Simple and dietary instruments specifically designed to be used in epidemiological or interventional studies in Japan are needed.

The Food Frequency Questionnaire was designed specifically for dental studies and assesses the frequency of snacking and cariogenic quality of snacks [16]. It has demonstrated reliability and validity.

The purpose of this paper is to present preliminary evidence of reliability and cross-cultural validity of a culturally appropriate Japanese version of the English language Food Frequency Questionnaire [16]. The specific objectives were: (1) to investigate its construct validity through a factor analysis and examination of internal consistency; (2) to determine test-retest reliability; and (3) to assess criterion validity in terms of the relationship with salivary mutans streptococci levels.

\section{Methods}

\section{Participants}

As part of a larger study of mother-child transmission of mutans streptococci, pregnant women at the time of enrollment were recruited at the Miyake Obstetrics and Gynecology Clinic in Okayama prefecture (western Japan) between January 2004 and June 2005. To be included, the participants had to be able to communicate in Japanese and have visited the OB-GYN clinic at least once during the third to fifth month of pregnancy. Participants were excluded if they reported antibiotic use during the prior month. The subjects comprised 355 pregnant women aged $19-43$ years (mean $29.2 \pm 4.2$ years). A separate convenience sample of 25 women aged 28-41 years (mean $34.0 \pm 3.0$ years) was recruited to participate in the test-retest reliability analysis via Ishihara Dental Clinic in Okayama based on the following criteria: the same age range between 19-43 years as the population for the validity analysis, absence of any disease that may influence nutritional status, the ability to complete the questionnaire.

The Okayama University Institutional Review Board approved the study and all participants gave their informed consent.

\section{Measures}

\section{Food frequency questionnaire}

The original English language questionnaire consists of 35 items requiring participants to recall how often, on average, they have consumed a given caries-related food during the past month ( 7 points, $0-6$, categories ranging from "never" to " 4 or more times per day"), and has established reliability and validity [16]. The English language questionnaire was translated in Japanese by a native speaker and then back translated into English by another native speaker to ensure comparability to the original form. Of them, 2 items, applesauce and breakfast drinks, were excluded because they were not familiar to the Japanese. Five items of traditional fresh and semi-dry confectioneries commonly consumed in Japan, such as bread filled with bean jam or fruit jam (An-pan or Jampan), rice cracker (Senbei), bun with a bean-jam filling (Manju), rice cake (Mochi), and bar of sweet jellied adzuki-bean paste(Youkan), were added to increase content validity. The Japanese version with 38 food items was then pretested and the translation modified. The final questionnaire in Japanese is in Figure 1. The questionnaire was scored by multiplying the frequency score for each item by a cariogenicity rating (3 points, $0-2$, "possibly cariostatic" to "highly cariogenic") based on the Palmer cariogenicity classification [17] and then summing to create the overall score that can possibly range from 0 to 378 . 


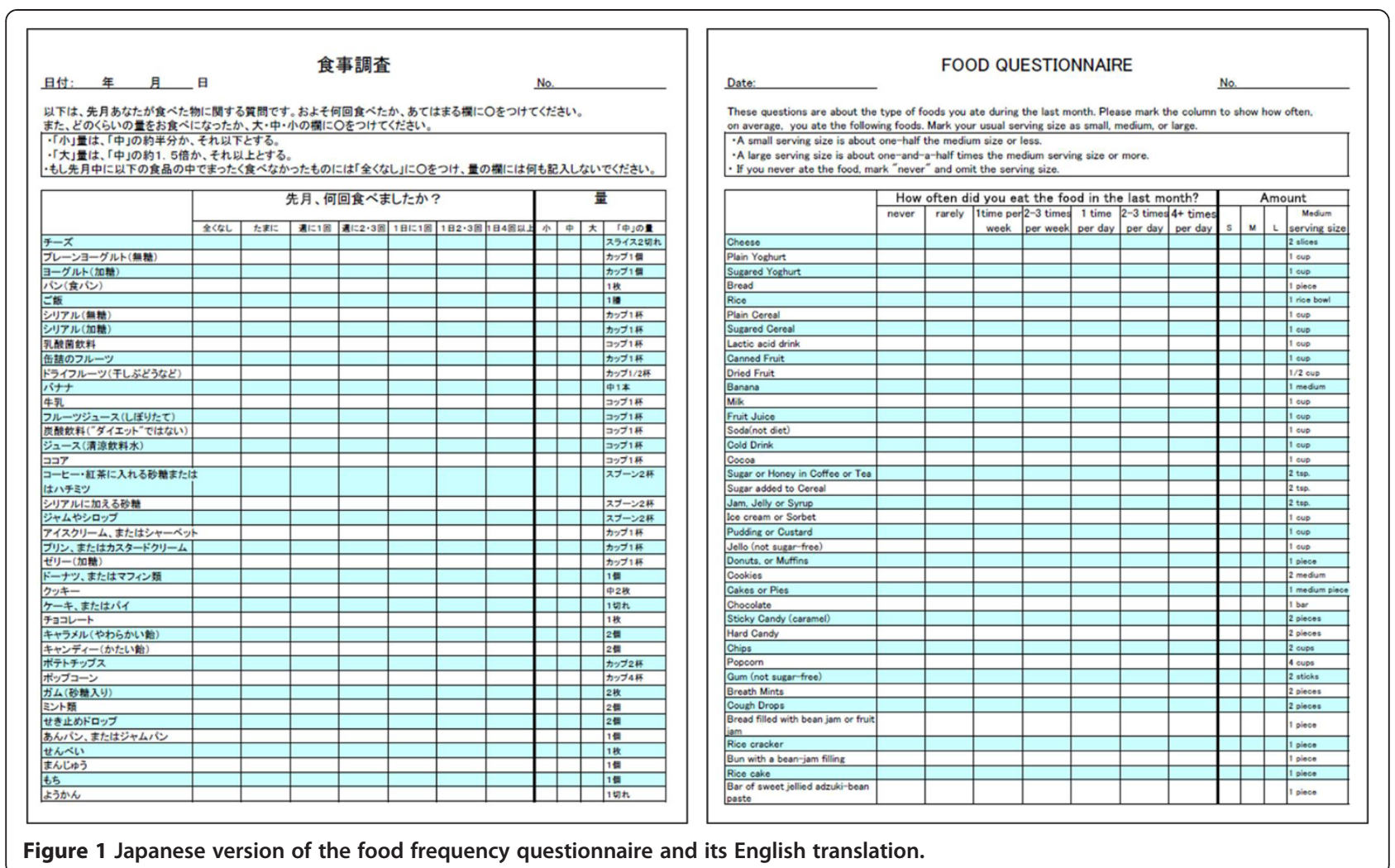

\section{Salivary mutans streptococci levels}

Salivary mutans streptococci level was assessed using the Dentocult SM Strip Mutans (Orion Diagnostica, Espoo, Finland). Participants refrained from having eating or drinking or brushing their teeth for at least $1 \mathrm{~h}$ prior to sampling. Each chewed a piece of paraffin for 1 minute and then swallowed the secreted saliva. Then the roughened side of the strip designed for salivary mutans assay was gently pressed against the tongue. The inoculated salivary strip was inserted into the culturing vial of Dentocult SM. Vials were transported to the lab for incubation. After incubation at $37^{\circ} \mathrm{C}$ for $48 \mathrm{~h}$, bacterial growth on the strip was assessed in comparison with the density chart provided by the manufacturer by a single researcher (C.S.). The intra-rater reliability of the assessments were established as follows; 20 strips of Dentocult SM which had been assessed were re-assessed a week later by the same researcher blinded to the previous result, and then the agreement between those results was calculated prior to study implementation. The resulting reliability was high $(\kappa>0.8)$. According to the manufacturer, categories of Strip Mutans were ' $0-1$ ' ' ' 2 ' ' ' 3 ', correspond to $<10^{5}, 10^{5}$ $10^{6}$, and $>10^{6} \mathrm{CFU} / \mathrm{mL}$ of saliva, respectively.

\section{Procedures}

For the validity study, the participants in the larger interventional study [18] completed the Food Frequency
Questionnaire and had their saliva sampled during an initial visit. In the reliability study, the participants completed the questionnaire in the waiting room. They were given a second copy of the questionnaire and asked to complete it again one week later and bring or mail back. This interval was chosen because the questions focused on the diet at a particular time and recall would obviously be worse over time.

\section{Analysis}

Distributions of the 38 items were examined to assess the degree of missing data. Although a total 400 participants were recruited, 355 questionnaires were complete and used in the validity sample. No missing data was found in test-retest reliability sample. Data were entered into the computer and checked for accuracy. Data management and analyses were conducted using SPSS ver. 19 (IBM SPSS Inc.). The internal consistency and test-retest reliability of the Japanese language Food Frequency Questionnaire were assessed using Cronbach's alpha and intraclass correlation coefficient (ICC), respectively. Newly developed measures can be accepted with Cronbach's alpha of $>0.5$, otherwise 0.7 should be the threshold [19]. ICCs were interpreted using the following criteria: $\mathrm{ICC}<0.4$, poor, $0.4<\mathrm{ICC}<0.75$, fair or good, ICC $>0.75$, excellent [20]. Factor analysis was used to examine dimensionality. Principal components analysis with Varimax rotation 
Table 1 Distribution of frequency scores in each food item $(n=355)$

\begin{tabular}{|c|c|c|c|c|c|c|c|}
\hline \multirow[t]{2}{*}{ Food item } & \multicolumn{7}{|c|}{$\%$ distribution of frequency scores } \\
\hline & 0 (never) & 1 (rarely) & $2(1 / w k)$ & $3(2-3 / w k)$ & 4 (1/dy) & 5 (2-3/dy) & 6 (4+/dy) \\
\hline \multicolumn{8}{|l|}{ Solid sugars } \\
\hline Donuts, or muffinns & 52.7 & 40.3 & 3.9 & 2.5 & 0.6 & 0 & 0 \\
\hline Pudding or custard & 39.0 & 49.4 & 6.8 & 4.5 & 0.3 & 0 & 0 \\
\hline Bread filled with bean & 63.3 & 30.8 & 2.3 & 3.4 & 0.3 & 0 & 0 \\
\hline \multicolumn{8}{|l|}{ jam or fruit jam } \\
\hline Bar of sweet jellied & 90.7 & 7.9 & 1.1 & 0.3 & 0 & 0 & 0 \\
\hline \multicolumn{8}{|l|}{ adzuki-bean paste } \\
\hline \multicolumn{8}{|l|}{ Solid and starchy sugars } \\
\hline Rice cake & 74.9 & 20.8 & 2.8 & 1.1 & 0.3 & 0 & 0 \\
\hline Bun with a bean-jam filling & 48.2 & 45.1 & 4.8 & 2.0 & 0 & 0 & 0 \\
\hline Popcorn & 89.0 & 10.5 & 0.3 & 0.3 & 0 & 0 & 0 \\
\hline Rice cracker & 40.0 & 44.8 & 7.0 & 7.0 & 0.8 & 0.3 & 0 \\
\hline Chocolate & 31.1 & 46.9 & 8.5 & 11.9 & 1.7 & 0 & 0 \\
\hline \multicolumn{8}{|l|}{ Liquid and semisolid sugars } \\
\hline Cold drink & 27.7 & 41.5 & 5.9 & 15.0 & 7.6 & 1.7 & 0.6 \\
\hline Soda (not diet) & 43.2 & 39.5 & 5.4 & 8.5 & 2.3 & 0.8 & 0.3 \\
\hline Ice cream or sorbet & 15.5 & 48.2 & 13.8 & 18.3 & 3.9 & 0.3 & 0 \\
\hline \multicolumn{8}{|c|}{ Sticky and slowly dissolving sugars } \\
\hline Hard candy & 37.7 & 41.1 & 2.0 & 10.1 & 5.1 & 3.1 & 0.8 \\
\hline Gum (not sugar-free) & 64.8 & 23.1 & 4.2 & 3.7 & 1.4 & 1.7 & 1.1 \\
\hline Sugar or honey in coffee/tea & 49.4 & 19.9 & 4.3 & 10.5 & 13.9 & 1.4 & 0.6 \\
\hline Sticky candy (caramel) & 82.0 & 15.2 & 1.1 & 1.1 & 0.3 & 0.3 & 0 \\
\hline \multicolumn{8}{|l|}{ Other } \\
\hline Cheese & 24.4 & 45.9 & 10.5 & 15.6 & 2.8 & 0.6 & 0.3 \\
\hline Plain yoghurt & 56.4 & 17.3 & 5.4 & 11.9 & 8.5 & 0.3 & 0.3 \\
\hline Sugared yoghurt & 27.9 & 29.9 & 11.7 & 20.2 & 9.4 & 0.9 & 0 \\
\hline Bread & 4.3 & 15.1 & 8.2 & 30.4 & 36.9 & 2.8 & 2.3 \\
\hline Rice & 1.2 & 2.7 & 0.6 & 4.4 & 17.7 & 69.3 & 4.1 \\
\hline Plain cereal & 95.2 & 3.4 & 0.9 & 0.6 & 0 & 0 & 0 \\
\hline Sugared cereal & 86.9 & 10.2 & 1.1 & 0.9 & 0.9 & 0 & 0 \\
\hline Lactic acid drink & 37.5 & 35.2 & 8.5 & 10.5 & 7.4 & 0.3 & 0.6 \\
\hline Canned fruit & 68.5 & 23.9 & 4.0 & 3.1 & 0.6 & 0 & 0 \\
\hline Dried fruit & 76.6 & 14.1 & 2.0 & 2.8 & 3.7 & 0.6 & 0.3 \\
\hline Banana & 26.3 & 42.9 & 8.5 & 16.1 & 4.5 & 0.6 & 1.1 \\
\hline Milk & 11.6 & 11.9 & 3.4 & 22.0 & 36.2 & 13.0 & 2.0 \\
\hline Fruit juice & 51.0 & 28.6 & 5.4 & 8.2 & 4.5 & 1.7 & 0.6 \\
\hline Cocoa & 64.9 & 19.8 & 4.5 & 5.1 & 5.4 & 0.3 & 0 \\
\hline Sugar added to cereal & 98.9 & 1.1 & 0 & 0 & 0 & 0 & 0 \\
\hline Jam, jelly or syrup & 57.6 & 22.3 & 4.2 & 9.6 & 5.6 & 0.3 & 0.3 \\
\hline Jello (not sugar-free) & 60.6 & 30.0 & 3.0 & 5.1 & 0.6 & 0.6 & 0 \\
\hline Cookies & 43.6 & 43.9 & 6.2 & 4.8 & 1.4 & 0 & 0 \\
\hline Cakes or pies & 27.6 & 65.4 & 5.4 & 1.7 & 0 & 0 & 0 \\
\hline
\end{tabular}


Table 1 Distribution of frequency scores in each food item $(n=355)$ (Continued)

\begin{tabular}{llllrrrr}
\hline Chips & 38.0 & 50.1 & 8.2 & 3.4 & 0.3 & 0 & 0 \\
Breath mints & 82.3 & 12.4 & 1.7 & 1.7 & 1.7 & 0.3 \\
Cough drops & 94.9 & 2.8 & 0.6 & 0.6 & 0 & 0.8 \\
\hline
\end{tabular}

Due to rounding error, some totals are not $100 \%$.

was employed [21]. Kaiser's criterion (eigenvalues > 1.0) and a visual examination of the scree plot were utilized to determine the number of components to retain. Internal consistency was assessed for the full scale and subscales developed from the factor analysis. Criterion validity was assessed by examining the relationship between the dietary cariogenicity score and Dentocult SM category using Spearman's correlation coefficient $\left(r_{s}\right)$ and the Kruskal-Wallis test.

\section{Results}

Finally 355 pregnant women completed the questionnaire. Forty-five women were excluded from the validity study because the questionnaires were not complete. The distribution of frequency score in each food item is given in Table 1 . The questionnaire took about 3-5 minutes to complete.

\section{Construct validity and internal consistency}

As results of the factor analysis for the pregnant women sample, by Kaiser's criterion, 13 factors had eigenvalues $>1$, which together accounted for $56.8 \%$ of variance in total scores. The scree plot confirmed the retention of the first four factors. Table 2 shows the factor loadings after rotation and the four factors. Factor I was termed solid sugars subscale because it included items pertaining to: donuts/ muffins, pudding/custard, bread filled with bean jam or fruit jam, and bar of sweet jellied adzuki-bean paste. Factor II was termed solid and starchy sugars subscale because it included items pertaining to: rice cake, bun with a beanjam filling, popcorn, rice cracker, and chocolate. Factor III was termed liquid and semisolid sugars subscale including items such as cold drink, not-diet soda, and ice cream/ sorbet. Factor IV was termed sticky and slowly dissolving sugars subscale including such as hard candy, notsugar-free gum, sugar/honey in coffee/tea, and sticky candy/caramel. Cronbach's alpha for the total scale was 0.67 . For each subscale, alphas were $0.61,0.58,0.56$, and 0.46 , respectively. For each subscale, mean cariogenicity subscores were $3.9(\mathrm{SD}=3.6$, range $0-24), 5.5(\mathrm{SD}=4.1$, range $0-26), 7.6(\mathrm{SD}=5.2$, range $0-30)$, and $6.6(\mathrm{SD}=6.1$, range $0-36)$, respectively.

\section{Test-retest reliability}

The mean dietary cariogenicity scores derived from the Food Frequency Questionnaire in Japanese for the first and second administrations were $47.4 \pm 14.1$ (range 25-83) and
$40.6 \pm 11.3$ (range 19-65). The test-retest reliability was high $(\mathrm{ICC}=0.70)$. Figure 2 is a scatter plot of the relationship between those scores.

\section{Criterion validity}

The mean dietary cariogenicity score derived from the Japanese version of the Food Frequency Questionnaire was $50.8 \pm 19.5$ (range 9-120) in the pregnant women sample. The distribution of Dentocult SM scores was $6.8 \%$ $(\mathrm{n}=24$, score $=0), 34.4 \%(\mathrm{n}=122$, score $=1), 39.4 \%(\mathrm{n}=$ 140 , score $=2)$, and $19.4 \%(n=69$, score $=3)$. Figure 3 shows a scatter plot of the relationship between dietary cariogenicity and Dentocult SM scores. The dietary cariogenicity score was positively correlated with measure of salivary mutans streptococci $\left(r_{s}=0.22, p<0.001\right)$. The cariogenicity subscore was also positively correlated with measure of salivary mutans streptococci in each subscale $\left(\mathrm{r}_{\mathrm{s}}=0.17, \mathrm{p}<0.01\right.$ for solid sugars subscale, $\mathrm{r}_{\mathrm{s}}=0.192$, $\mathrm{p}<0.001$ for solid and starchy sugars subscale, $\mathrm{r}_{\mathrm{s}}=0.169$, $\mathrm{p}<0.01$ for liquid and semisolid sugars subscale, $\mathrm{r}_{\mathrm{s}}=0.086$, $\mathrm{p}=0.106$ for sticky and slowly dissolving sugars subscale). Table 3 gives the mean dietary cariogenicity score for each category of Dentocult SM score. Individuals with higher scores were more likely to have higher dietary cariogenicity scores ( $\mathrm{p}<0.001$; Kruskal-Wallis test).

\section{Discussion}

This study provides preliminary evidence for reliability and cross-cultural validity of the Japanese language version of the Food Frequency Questionnaire specifically created for studies of dental caries. Factor analysis suggested four subscales: "solid sugars", "solid and starchy sugars", "liquid and semisolid sugars", and "sticky and slowly dissolving sugars", corresponding to an established classification of sugary foods by extent of oral retention [17]. The reliability and validity of the Japanese language Food Frequency Questionnaire is good, as compared with other food frequency questionnaires [22]. Criterion validity was established for the Japanese language version by examining the association between the Food Frequency Questionnaire cariogenicity score and salivary mutans streptococci levels. The Dentocult SM measure has been shown to be a reasonable surrogate for dental caries $[23,24]$. The questionnaire is simple and is quickly completed. The questionnaire containing food items, most of which had derived from USA, reflected caries risk indicator among Japanese. The finding implies that 
Table 2 Factor loadings, eigenvalues, variance explained from principal component analysis with Varimax rotation, and Cronbach's alpha for each factor for the Japanese version of the food frequency questionnaire in Japanese $(n=355)$

\begin{tabular}{|c|c|c|c|c|}
\hline & \multicolumn{4}{|c|}{ Factor loading component } \\
\hline & $\mathrm{I}^{\mathrm{a}}$ & II $^{\mathbf{b}}$ & $\mathrm{III}^{\mathrm{c}}$ & $\mathrm{IV}^{\mathrm{d}}$ \\
\hline Donuts, or muffins & 0.704 & 0.030 & 0.111 & 0.091 \\
\hline Pudding or custard & 0.624 & -0.111 & 0.322 & 0.134 \\
\hline Bread filled with bean jam or fruit jam & 0.622 & 0.712 & 0.095 & -0.229 \\
\hline Bar of sweet jellied adzuki-bean paste & 0.480 & 0.286 & -0.046 & 0.025 \\
\hline Rice cake & -0.109 & 0.705 & -0.111 & -0.106 \\
\hline Bun with a bean-jam filling & 0.379 & 0.588 & -0.022 & 0.013 \\
\hline Popcorn & 0.095 & 0.554 & 0.085 & 0.184 \\
\hline Rice cracker & 0.238 & 0.472 & 0.033 & 0.063 \\
\hline Chocolate & 0.173 & 0.420 & 0.124 & 0.182 \\
\hline Cold drink & 0.075 & 0.019 & 0.696 & 0.129 \\
\hline Soda (not diet) & 0.148 & -0.011 & 0.614 & 0.133 \\
\hline Ice cream or sorbet & 0.183 & 0.038 & 0.612 & 0.011 \\
\hline Hard candy & -0.016 & 0.043 & 0.176 & 0.679 \\
\hline Gum (not sugar-free) & 0.083 & -0.026 & 0.221 & 0.648 \\
\hline Sugar or honey in coffee or tea & -0.112 & 0.065 & 0.083 & 0.512 \\
\hline Sticky candy (caramel) & 0.071 & 0.157 & -0.105 & 0.415 \\
\hline Cheese & 0.139 & -0.009 & -0.053 & 0.007 \\
\hline Plain yoghurt & -0.052 & 0.078 & -0.094 & 0.037 \\
\hline Sugared yoghurt & 0.208 & -0.076 & -0.134 & 0.127 \\
\hline Bread & 0.192 & 0.047 & -0.036 & 0.020 \\
\hline Rice & -0.050 & 0.039 & 0.006 & -0.039 \\
\hline Plain cereal & -0.073 & 0.076 & 0.048 & -0.051 \\
\hline Sugared cereal & 0.033 & -0.047 & 0.140 & -0.007 \\
\hline Lactic acid drink & 0.004 & 0.103 & 0.042 & 0.071 \\
\hline Canned fruit & 0.072 & 0.037 & 0.042 & 0.052 \\
\hline Dried fruit & 0.123 & -0.112 & -0.085 & 0.088 \\
\hline Banana & 0.165 & -0.113 & -0.213 & -0.012 \\
\hline Milk & -0.045 & -0.065 & -0.101 & 0.067 \\
\hline Fruit juice & -0.046 & -0.082 & 0.155 & 0.140 \\
\hline Cocoa & -0.023 & 0.177 & -0.208 & 0.347 \\
\hline Sugar added to cereal & -0.048 & 0.067 & 0.070 & -0.011 \\
\hline Jam, jelly or syrup & -0.184 & 0.337 & 0.244 & -0.100 \\
\hline Jello (not sugar-free) & 0.180 & -0.018 & 0.326 & -0.081 \\
\hline Cookies & 0.341 & 0.269 & -0.026 & 0.140 \\
\hline Cakes or pies & 0.382 & 0.235 & 0.158 & 0.171 \\
\hline Chips & 0.072 & 0.320 & 0.174 & 0.069 \\
\hline Breath mints & 0.155 & 0.071 & -0.069 & 0.347 \\
\hline Cough drops & -0.096 & 0.019 & 0.064 & 0.042 \\
\hline
\end{tabular}

Table 2 Factor loadings, eigenvalues, variance explained from principal component analysis with Varimax rotation, and Cronbach's alpha for each factor for the Japanese version of the food frequency questionnaire in Japanese $(\mathbf{n}=\mathbf{3 5 5})$ (Continued)

\begin{tabular}{lcccc}
\hline Eigenvalue & 4.055 & 2.183 & 1.898 & 1.827 \\
\% variance & 10.671 & 5.745 & 4.996 & 4.807 \\
Cronbach's alpha & 0.61 & 0.58 & 0.56 & 0.46 \\
\hline
\end{tabular}

"Factor I is called "solid sugars subscale".

"Factor II is called "solid and starchy sugars subscale".

"Factor III is called "liquid and semisolid sugars subscale".

"Factor IV is called "sticky and slowly dissolving sugars subscale".

Factor loadings over 0.400 appear in bold.

this questionnaire has potential to compare the caries risk levels among the other cultures where these foods have become part of the diet.

The validation study was carried out as part of a larger study of the transmission of mutans streptococci from mother to child [18]. This transmission is an important factor in the development of tooth decay in children. Before any intervention in this study, the women completed the questionnaire. Dietary preferences often change in pregnant women and may lead to frequent intake of cariogenic foods. Thus, they were chosen for this initial validation study.

This study has strengths. An extensively studied instrument designed specifically for looking at the relationship between diet and tooth decay served as the basis for the Japanese instrument. Moreover, the microbiological assessment was used as a surrogate gold standard for dental caries. It is a well-established

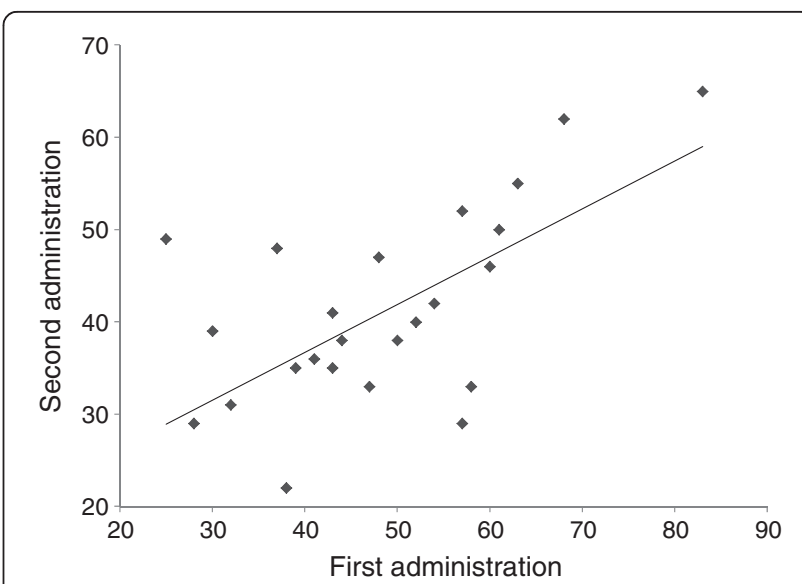

Figure 2 Scatter plot and correlation relationship of dietary cariogenicity score between the first and second administrations for test-retest reliability. $I C C=0.70, n=25$. 


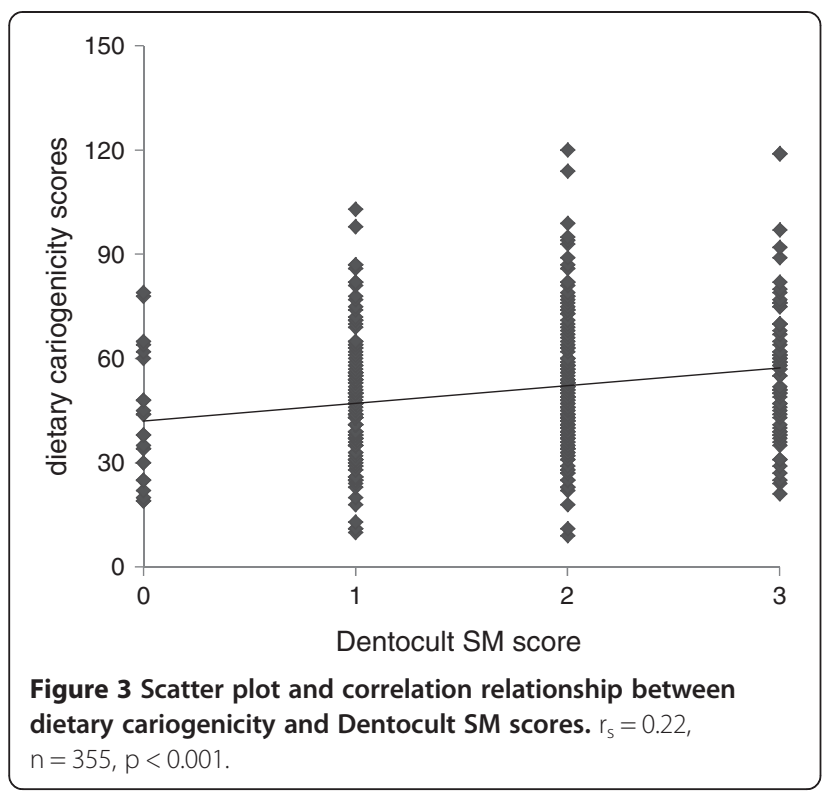

measure of the risk of transmission from mother to child $[18,25]$. However, other factors such as hormonal changes and genetic disposition may have moderated the results. Future work on the instrumentation in Japanese should include a broader group of participants. Nevertheless, the Japanese version of the Food Frequency Questionnaire exhibited good test-retest reliability, acceptable internal consistency, and good construct and criterion validity. These preliminary findings suggest the applicability of the Japanese version of the instrument in dental caries research.

\section{Conclusions}

The Japanese version of the Food Frequency Questionnaire is a reliable and valid instrument to assess dietary intake in relation to dental caries risk, and can operate the same in Japan as it does in USA culture.

Table 3 Mean dietary cariogenicity score* for each category of Dentocult SM scores $(n=355)$

\begin{tabular}{ccccc}
\hline & \multicolumn{4}{c}{ Dentocult SM score } \\
\cline { 2 - 5 } & $\mathbf{0}$ & $\mathbf{1}$ & $\mathbf{2}$ & $\mathbf{3}$ \\
\hline Mean \pm SD & $41.0 \pm 18.0$ & $47.5 \pm 18.3$ & $51.8 \pm 19.5$ & $57.8 \pm 20.1$ \\
$\mathrm{n}$ & 24 & 122 & 140 & 69 \\
\hline
\end{tabular}

$\mathrm{P}<0.001$, Kruskal-Wallis test.

*The dietary cariogenicity score was calculated by multiplying the frequency score for each item by a cariogenicity rating (3 points, $0-2$, "possibly cariostatic" to "highly cariogenic") based on the Palmer cariogenicity classification and then summing to create the overall score.

\section{Competing interests}

The authors declare that they have no competing interests.

\section{Authors' contributions}

CS contributed to data collection, statistical analyses, and writing of the manuscript. YN was principal investigator of the research, conceptualized the paper, conducted statistical analyses with primary responsibility, and wrote the final paper. PM supervised preparing the conceptual framework for the paper and contributed to the overall manuscript. KM contributed to data collection and statistical analyses. MMN oversaw the procedures. All authors read and approved the final manuscript.

\section{Acknowledgements}

We thank DH Hiroe Takemoto, and Drs. Yukako Mori, Mari Kaji, Kyoko Moriya, Mihoe Takimura and Ying Ji for assistance. We acknowledge Dr. Kaoru Miyake, the Head of Miyake OB-GYN Clinic for his collaboration. This project was supported, part by, by a Grant-in-Aid KAKENHI (15791208 to Y.N.) from the Ministry of Education, Culture, Sports, Science and Technology, Japan, and Award Number U54DE019346 from the National Institute of Dental \& Craniofacial Research, National Institutes of Health, Bethesda, MD USA. The content is solely the responsibility of the authors and does not necessarily represent the official views of the National Institute of Dental \& Craniofacial Research or the National Institutes of Health.

\section{Author details}

${ }^{1}$ Department of Pediatric Dentistry, Okayama University Graduate School of Medicine, Dentistry and Pharmaceutical Sciences, Okayama, Japan.

${ }^{2}$ Department of Oral Health Sciences, University of Washington, Seattle, WA, USA.

Received: 3 October 2013 Accepted: 19 December 2013

Published: 2 January 2014

\section{References}

1. Sreebny LM: Sugar availability, sugar consumption and dental caries. Community Dent Oral Epidemiol 1982, 10(1):1-7.

2. Kalsbeek H, Verrips GH: Consumption of sweet snacks and caries experience of primary school children. Caries Res 1994, 28(6):477-483.

3. Gustafsson BE, Quensel CE, Lanke LS, Lundqvist C, Grahnen H, Bonow BE, Krasse B: The Vipeholm dental caries study; the effect of different levels of carbohydrate intake on caries activity in 436 individuals observed for five years. Acta Odontol Scand 1954, 11(3-4):232-264.

4. Palmer CA, Kent R, Loo CY, Hughes CV, Stutius E, Pradhan N, Dahlan M, Kanasi E, Vasquez SSA, Tanner ACR: Diet and caries-associated bacteria in severe early childhood caries. J Dent Res 2010, 89(11):1224-1229.

5. Evans EW, Hayes C, Palmer CA, Bermudez OI, Naumova EN, Cohen SA, Must A: Development of a pediatric cariogenicity index. J Public Health Dent 2013, 73(2):179-186.

6. Shirota T, Yoshizumi F: A study on convenient dietary assessment. Nihon Koshu Eisei Zasshi 1990, 37(2):100-108.

7. Yoshihara A, Watanabe R, Hanada N, Miyazaki H: A longitudinal study of the relationship between diet intake and dental caries and periodontal disease in elderly Japanese subjects. Gerodontology 2009, 26(2):130-136.

8. Tanaka K, Miyake Y, Sasaki S, Ohya Y, Miyamoto S, Matsunaga I, Yoshida T, Hirota Y, Oda H: Magnesium intake is inversely associated with the prevalence of tooth loss in Japanese pregnant women: the Osaka Maternal and Child Health Study. Magnes Res 2006, 19(4):268-275.

9. Tanaka K, Miyake Y, Sasaki S, Ohya Y, Matsunaga I, Yoshida T, Hirota Y, Oda $H$ : Relationship between intake of vegetables, fruit, and grains and the prevalence of tooth loss in Japanese women. J Nutr Sci Vitaminol (Tokyo) 2007, 53(6):522-528.

10. Sasaki S, Yanagibori R, Amano K: Self-administered diet history questionnaire developed for health education: a relative validation of the test-version by comparison with 3-day diet record in women. J Epidemiol 1998, 8(4):203-215.

11. Vellas B, Guigoz Y, Garry PJ, Nourhashemi F, Bennahum D, Lauque S, Albarede JL: The Mini Nutritional Assessment (MNA) and its use in grading the nutritional state of elderly patients. Nutrition 1999, 15(2):116-122

12. Rubenstein $L Z$, Harker JO, Salvà A, Guigoz Y, Vellas B: Screening for undernutrition in geriatric practice: developing the short-form 
mini-nutritional assessment (MNA-SF). J Gerontol A Biol Sci Med Sci 2001, 56(6):M366-M372.

13. Furuta M, Komiya-Nonaka M, Akifusa S, Shimazaki Y, Adachi M, Kinoshita T, Kikutani T, Yamashita Y: Interrelationship of oral health status, swallowing function, nutritional status, and cognitive ability with activities of daily living in Japanese elderly people receiving home care services due to physical disabilities. Community Dent Oral Epidemiol 2013, 41(2):173-181.

14. Kuzuya M, Kanda S, Koike T, Suzuki Y, Satake S, Iguchi A: Evaluation of MiniNutritional Assessment for Japanese frail elderly. Nutrition 2005, 21(4):498-503.

15. Yokoyama Y, Kakudate N, Sumida F, Matsumoto Y, Gilbert GH, Gordan W: Dentists's dietary perception and practice patterns in a dental practice-based research network. PLos One 2013, 8(3):e59615.

16. Evens CC: Snacking patterns as a risk factor for early childhood caries. PhD Thesis. University of Washington, 1997.

17. Papas AS, Palmer CA, Rounds MC, Herman J, McGandy RB, Hartz SC, Russell RM, DePaola P: Longitudinal relationships between nutrition and oral health. Ann N Y Acad Sci 1989, 561:124-142.

18. Nakai Y, Shinga-Ishihara C, Kaji M, Moriya K, Murakami-Yamanaka K, Takimura $\mathrm{M}:$ Xylitol gum and maternal transmission of mutans streptococci. J Dent Res 2010, 89(1):56-60.

19. Nunally JC, Bernstein IH: The assessment of reliability. In Psychometric theory. 3rd edition. New York: McGraw-Hill; 1994:248-290.

20. Shrout PE, Fleiss JL: Intraclass correlations: uses in assessing rater reliability. Psychol Bull 1979, 86(2):420-428.

21. Kleinknecht RA, Thorndike RM, McGlynn FD, Harkavy J: Factor analysis of the dental fear survey with cross validation. JADA 1984, 86:842-848.

22. Kolodziejczyk JK, Merchant G, Norman GJ: Reliability and validity of child/ qdolescent food frequency questionnaires that assess foods and/or food groups. JPGN 2012, 55(1):4-13.

23. Tanabe Y, Park JH, Tinanoff N, Turng BF, Lilli H, Minah GE: Comparison of chairside microbiological screening systems and conventional selective media in children with and without visible dental caries. Pediatr Dent 2006, 28(4):363-368.

24. Twetman S, Mattiasson A, Varela RJ, Bratthall D: Mutans streptococci in saliva and dental caries in children living in a high and a low fluoride area. Oral Microbiol Immunol 1990, 5:169-171.

25. Thorild I, Lindau B, Twetman S: Effect of maternal use of chewing gums containing xylitol, chlorhexidine or fluoride on mutans streptococci colonization in the mother's infant children. Oral Health Prev Dent 2003, 1(1):53-57.

doi:10.1186/1472-6831-14-1

Cite this article as: Shinga-Ishihara et al:: Cross-cultural validity of a dietary questionnaire for studies of dental caries risk in Japanese. BMC Oral Health 2014 14:1.

\section{Submit your next manuscript to BioMed Central and take full advantage of:}

- Convenient online submission

- Thorough peer review

- No space constraints or color figure charges

- Immediate publication on acceptance

- Inclusion in PubMed, CAS, Scopus and Google Scholar

- Research which is freely available for redistribution 